\title{
Isolation and Characterization of Urease Utilizing Bacteria to Produce Biocement
}

\author{
Varalakshmi ${ }^{1,}$ Anchana devi ${ }^{2}$ \\ ${ }^{1,2}$ (PG \& Research Department of Biotechnology, Women's Christian College, Chennai 600 006, Tamilnadu,)
}

\begin{abstract}
Cement is a material which maintains durability of building structure and conservation of cultural heritage. Although hundreds and thousands of successful concrete and buildings are annually constructed worldwide, there are large number of concrete structures (including historical monuments), that deteriorates or become unsafe in loading. Hence, in order to overcome the short comings of conventional sealing agent, materials with self healing capability can be used effectively. Use of urease producing microbes addresses these problems effectively as these continue to survive and grow within the concrete structure after the initial use. Urease help in mineralization of Calcium carbonate, by hydrolyzing urea present in the environment. It releases carbon dioxide from urease activity, bacteria are able to use urea as sole nitrogen source and produce ammonia which increases the $\mathrm{pH}$ in the proximal environment causing $\mathrm{Ca}^{2+}$ and $\mathrm{Co}^{3+}$ to precipitate as $\mathrm{Ca}_{2} \mathrm{Co}_{3}$. These unique proprieties make it particularly suitable for many applications in civil engineering (concretestructures ,plasters, mortars, prefabricated elements, refractory elements, bricks, and stones).The Microbes isolated from the sewage samples is tested for Urea hydrolyzing and tolerance capacities. Urease positive bacteria is used to produce Biocement in-vitro by incubating it for one week then the precipitated biomass is filtered and air dried, the biomass is checked for its porosity using Scanning Electron Microscope comparing to the ordinary cement
\end{abstract}

Keywords: Biocement, Proteus Sp., Urease Tolerance, SEM

\section{Introduction}

The constant development in the field of civil engineering and the growth of industrial activity have created growing demand of materials for the construction industry. All building materials are porous, this porosity of building material along with moisture and other harmful chemicals such as acids, chlorides and sulfates affect the material and reduce their strength and life. The Urease producing organisms addresses a solution to the growing problem in a natural way by precipitating the Biocement in Hard water .

\subsection{Organisms Involved In Calcium Carbonate Precipitation:}

Microbiologically induced calcium carbonate precipitation (MICP) is a bio-geochemical process that induces calcium carbonate precipitation within the soil matrix. Calcium carbonate can be precipitated in three polymorphic forms, which in the order of their usual stabilities are calcite, aragonite and vaterite. The main groups of microorganisms that can induce the carbonate precipitation are photosynthetic microorganisms such as Cyanobacteria and Microalgae; Sulfate-reducing bacteria and some species of microorganisms involved in nitrogen cycle. Several mechanisms have been identified by which bacteria can induce the calcium carbonate precipitation, including urea hydrolysis, denitrification, sulphate production, and iron reduction. Two different pathways, or Autotrophic and Heterotrophic pathways, through which calcium carbonate is produced, have been identified. However, all pathways result in depletion of carbon dioxide and favoring calcium carbonate precipitation. In heterotrophic pathway metabolic cycles involved are the nitrogen cycle and the sulfur cycle. Several applications of this process have been proposed, such as remediation of cracks and corrosion prevention in concrete.

\subsection{Ureolysis Or Degradation Of Urea}

The microbial urease hydrolysis urea into Ammonium and Carbonate. One mole of urea is hydrolyzed intracellularly to Ammonia and Carbamicacid ,then forms bicarbonate, Ammonium and hydroxide ions in water .The production of hydroxide ions results in the increase of $\mathrm{pH}$, which in turn can shift the bicarbonate equilibrium, resulting in the formation of carbonate ions. The produced carbonate ions precipitates in the presence of calcium ions as calcium carbonate crystals

\subsection{Determination Of Water Hardness And Biocement Production :}

The total water hardness is determined by measuring the calcium and magnesium ions in water samples by a simple titration, the sample is first adjusted to $\mathrm{pH}$ of 10 using sodium hydroxide and few drops of Erichrome black indicator is added and titrated against $0.01 \mathrm{M}$ sodium ethylene diamine tetra acetate (EDTA). 
The change of colour from red to blue indicates the endpoint of titration. More the hardness of water aids in efficient precipitation of Calcium ions.

The present study attempts to develop suitable bacterial strains with maximum urease activity to act as catalyst in calcium -rich water samples (hard water) as a natural source to reduce the water hardness and produce Biocement as a valuable material.

\section{Methodology :}

Isolation and Characterization of Microbes from Sewage Sample:

The organisms were isolated from sewage sample and cultured on Nutrient agar medium, MacConkey agar medium, Mannitol salt agar medium and morphologically identified by using Gram staining technique. Further, characterization of organisms was carried out by various biochemical test and the results were tabulated

\section{Urease Test}

This test ,demonstrates that the unknown microbe has capability to produce Urease .This enzyme splits off ammonia from the urea molecule. Urea broth is a buffered solutions of yeast extract and urea .It also contains phenol red as a $\mathrm{pH}$ indicator. Since urea is unstable and breaks down on autoclave, It is usually sterilized by filtration . The medium is know as Christensen's agar medium

This test is performed to determine whether the organism contains the urease enzyme and has capability to utilize urea.

\section{Determination Of Water Hardness By EDTA Titration:}

The sample is first adjusted to $\mathrm{pH}$ of 10 using sodium hydroxide buffer solution. A few drops of Eriochome black $(0.5 \% \mathrm{wt} / \mathrm{vol})$ indicator was added and sample was titrated against $0.01 \mathrm{M}$ of sodium ethylene diamine tetra acetate(EDTA). EDTA draws the calcium and magnesium ions into a complex, so neither one has free ions in solution. The indicator initially turns red in presence of calcium and magnesium then it turns to metallic blue when enough EDTA solution has been added to combine with all Calcium and Magnesium. The total hardness of the water sample is calculated using the precise volume of EDTA solution added when the indicator changes the color. The calcium carbonate concentration was calculated according to the following equation:

$\mathrm{Ca}_{2} \mathrm{Co}_{3}(\mathrm{Mg} / \mathrm{l})=\left[\right.$ Vol. $\operatorname{EDTA}(\mathrm{ml}) / \mathrm{sample}$ volume $(\mathrm{L}) *\left[\mathrm{Ca}_{2} \mathrm{Co}_{3}(1 \mathrm{~mol}) / \operatorname{EDTA}(\mathrm{mol})\right.$.

\section{Urea Hydrolysis Phase Test}

$100 \mathrm{ml}$ of Urea agar medium was prepared using distilled water and filter sterilized $(0.45$-mm pore size). The agar was suspended in $900 \mathrm{ml}$ of distilled water, boiled to dissolve completely, and autoclaved at $121^{\circ} \mathrm{C}$ and 15 psi for 15 minutes. Aseptically $100 \mathrm{ml}$ of filter-sterilized urea base was added to the cooled agar solution and mixed thoroughly. The medium was distributed 4 to $5 \mathrm{ml}$ per sterile tube (13 x $100 \mathrm{~mm})$ and slant were prepared.The isolated organisms were inoculated in the urea broth and streaked on to the urea plate, the plates and tubes are incubated for 1 week.

\section{Urea- Tolerance Levels Of Bacterial Strains}

The best urea hydrolyser inoculums (3\%) was added to $1,1.5,2,2.5,3,3.5$, and $4 \mathrm{M}$ urea concentration and incubated at $37^{\circ} \mathrm{C}$. The visual turbidity was determined by cell cultures density at $600 \mathrm{~nm}$ using UV spectrophotometer.

\section{Mass Productionof Biocement From Hard Water And Soft Water}

To $500 \mathrm{ml}$ of water samples, $100 \mathrm{ml}(3 \mathrm{M})$ concentrations of filtered urea and $100 \mathrm{ml}$ inoculums were added and incubated for one week at $37^{\circ} \mathrm{C}$. After incubation the deposits of calcium carbonate was filtered using normal filter paper. After filtration the paper containing the deposits is kept inside the hot air oven at $35^{\circ} \mathrm{C}$ for $6 \mathrm{hrs}$.

\section{Characterization Of Biocement}

The Bacterial dry mass was obtained and analyzed for porosity using Scanning Electron Microscope

\section{Isolation And Identification Of Microorganism's:}

\section{Result And Discussion}

The isolated colonies from the Nutrient agar, MacConkey agar, and Mannitol salt agar were picked out and studied for colony morphology and staining procedures were carried out. The predominantly found bacteria were tabulated(Table 1) (Figure 1)

Table 1: COLONY MORPHOLOGYOF ORGANISM. 


\begin{tabular}{|c|c|}
\hline ORGANISM & COLONY MORPHOLOGY \\
\hline Proteus vulgaris & Rod shaped, Thin, blue gray, spreading growth. \\
\hline Straphylococcos aureus & Cocci, thin, even growth, Acid, rapid reduction \\
\hline Klebsiella pnemoniae & Rod shaped, slimy, white, translucent, raised growth \\
\hline
\end{tabular}

Figure 1:Isolation and identification of microorganisms
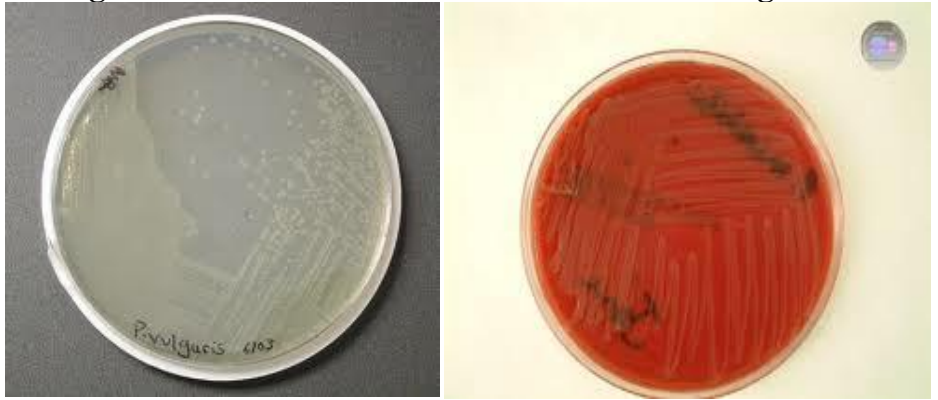

Organism: Proteus sp

organism: Staphylococcus aureus

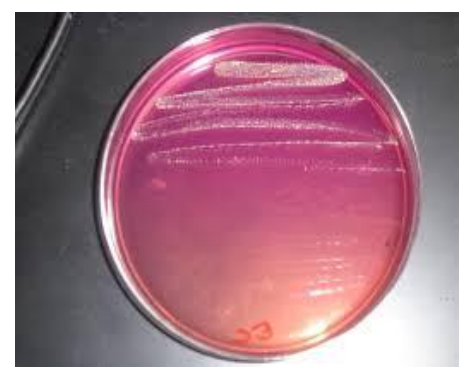

Organism: Klebsiella pnemoniae

\section{Urea Hydrolysis Test:}

The colonies of strains were cultured on urea agar medium; the tubes were incubated at $37^{\circ} \mathrm{C}$ for 48 hours. A change of colour in the media from yellow to pink was observed and it indicates the presence of urease enzyme. (Figure 2)

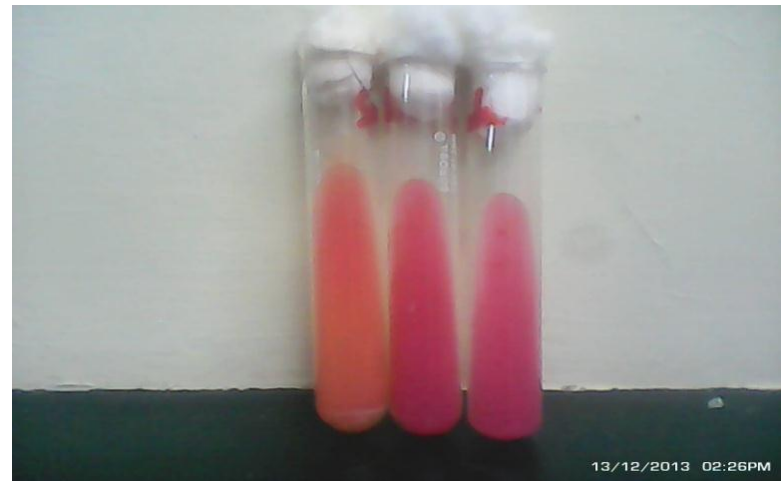

Figure 2 : Urea Hydrolysis Test

The urease positive bacteria changes the $\mathrm{pH}$ of the urea agar medium. The up taking of the urea present in the medium by organisms that changes the colour of media from yellow to pink. Three main group of organism's including photosynthetic organism, sulfate reducing bacteria and nitrifying bacteria that hydrolysis urea.

\section{Determination Of Water Hardness:}

The EDTA draws the calcium and magnesium ions into a complex which is present in the water sample, so neither ions are free in the solution.

Hardness In Sea Water: The change of colour from wine red to steel blue by reducing EDTA was observed. 
Total hardness in $20 \mathrm{ml}$ of sea water $=55 \mathrm{mg} / \mathrm{ml}$

Hardness In Soft Water :The change of colour from wine red to steel blue by reducing EDTA was observed. Total hardness in $20 \mathrm{ml}$ of sea water $=17.5 \mathrm{mg} / \mathrm{ml}$

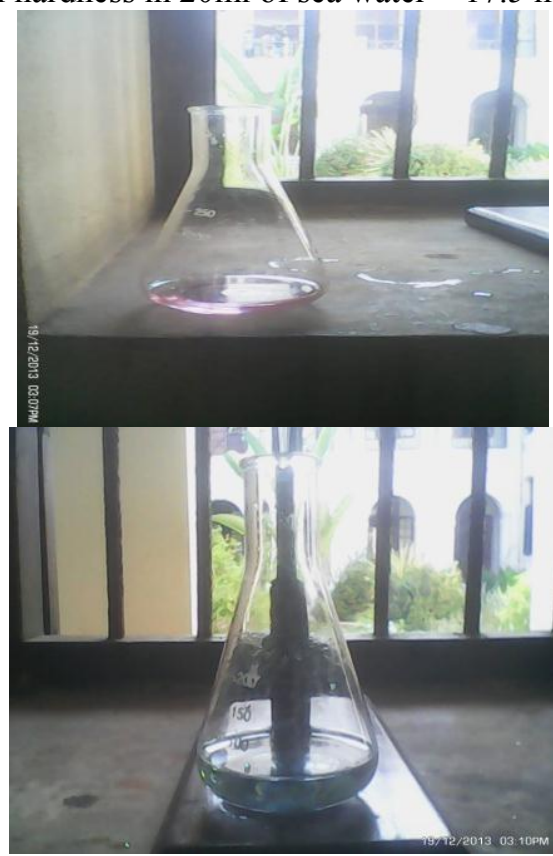

Figure 3 : Determination Of Water Hardness By EDTA Titration

The sea water has more calcium, magnesium and mineral ions when compared to the soft water and so it was confirmed that the hardness of sea water is greater than the soft water. This Confirms that the calcium deposits in the seawater is more than the soft water

\section{Urea Tolerance:}

The three bacterial strains ( Proteus sp, Staphylococcus sp,Klebsiella sp) were checked for the best urea tolerance capability by inoculating the medium, containing urea at different concentrations and OD is determined at $600 \mathrm{~nm}$ for its cell culture density, and the graph was plotted and observations were made.

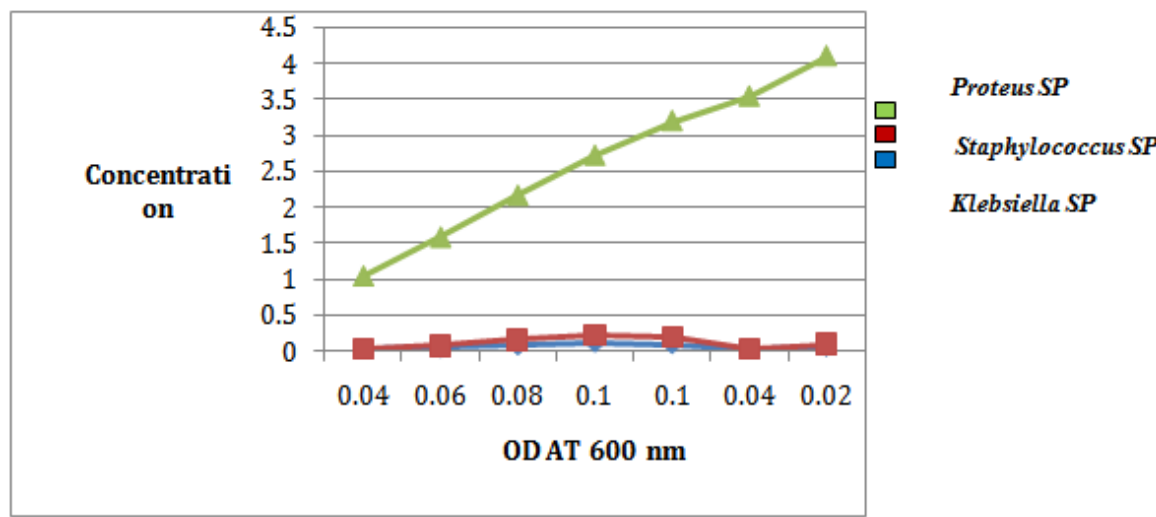

Figure 4 : Urea Tolerance Graph

By observing the urea tolerance graph, and comparing the other two bacterial strains Proteus sphad the highest urea tolerance level upto a concentration of $3.5 \mathrm{gm} / \mathrm{ml}$

\section{Mass Production Of Biocement}

The Calcium carbonate precipitation in sea water was more than the soft water, it has been proved that the hardness of sea water is greater than the soft water and Proteus sporganism precipitated Calcium carbonate at the higher amount. $500 \mathrm{ml}$ of sea water produced 5 grams of biomass (Figure 5).Biocement was produced at 
the incubation of one week.

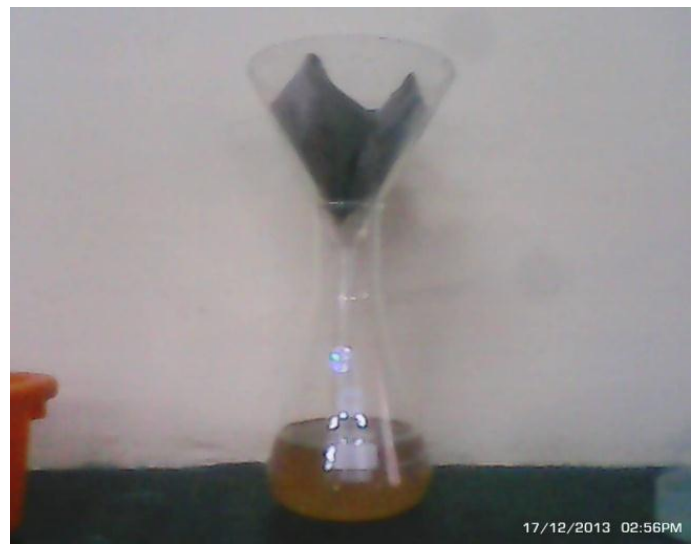

Figure 5:MassProduction of Biocement

Comparision Of Biocement And Common Cement Structures By Scanning Electron Microscope:

Studies on porosity and morphological characterization was determined using the technique of Scanning Electron Microscopy which consists of agglomerates of thin particles.

Figure 6 :SEM - Soft water sample

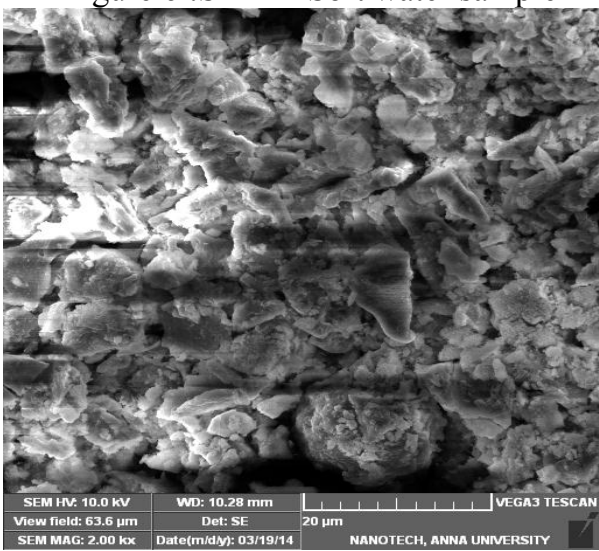

Figure 7: SEM -Sea water sample

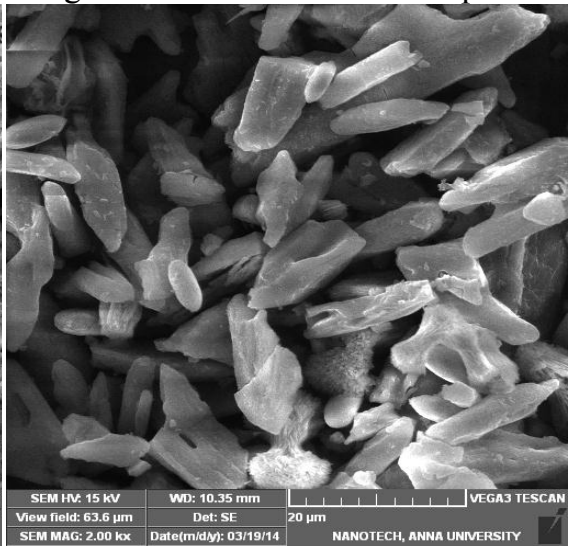

Scanning Electron Microscopy detected biocement produced from the two water samples were dispersed homogeneously (fig 6). The SEM image showed that the precipitated crystals of sea water were bigger than $20 \mu \mathrm{m}$ which formed clusters and more aggregated deposits when compared to $50 \mu \mathrm{m}$ which was observed in soft water sample, the porosity of sea water was much less when compared to the soft water sample (fig 7).

\section{Conclusion}

The goal of the present study was to produce a Calcium carbonate biomass precipitate from the natural hard water by urea hydrolyzing bacteria's (Proteus sp, Staphylococcus sp and Klebsiella sp). It was evident that the hard water had a higher amount of precipitation of calcium carbonate when compared to soft water sample where the porosity was also less, which makes it an evident material to be used in construction of civil works and bypasses the tedious process of conventional cement production and works in a cost effective way .

\section{References}

[1]. Naucencet, chahal'Anita Rajor\&Rafatsiddique "Calcium carbonate precipitation by different Bacterial strains" African journal of Biotechnology, volume.10(42);2001Page :8359 - 8372 .

[2]. Anita khanafari, faribaniari khans \&AbssAkhavanSepahy "An investigation of Biocement production from Hardwater" Middle-east journal of scientific research volume.7 (6)2011);Page: 1990-9233.

[3]. M.cecilliayappert, Donald B. Dupre"Complexometric Titrations: - competition of complexing Agents in the Determination of water hardness with EDTA" Journal of chemical education, vol3(1) 1997 ;Page: 1421-1422

[4]. Malcolm B. Burbank, Thomas, j.weaver, C.Barbarge, Williams .D \& Ronald L.Crawford“Urease activity of ureolylic Bacteria Isolated from six soils in which calcite was precipitated by indigenous Bacteria" Geomicrobiology Journal, Volume. (29), 2012;Page: 389-395

[5]. Williem de muynck, Dieter Debrouwer, Nele De Belie z, willy verstraete "Bacterial carbonate precipitation improves the durability of cementitious material" Cement and concreateresearch,volume.(38) 2008 ; Page: 1005-1014. 
[6]. Willem de moynck, Nele De Belic Z, willyverstraete "Microbial carbonate precipitation in construction materials a review" Ecological Engineering, Volume (36), .2010; Pages 118-136.

[7]. Mutlag AL-Thawadi "ureolytic bacteria and calcium carbonate formation as a mechanism of strength enhancement of sand" Design for scientific Renaissance volume.(1)2011;Page: 156-345

[8]. AdlrenneJ.Phillips, RotrinGerlach, Ellenlau "Engineering applications of ureolyticbiomineralization a review" Biofueling:The journal of Bioadhension and Biofilm Research volume. (29) 2013 ;Page: 715-733

[9]. Emil zolotoyabko, Boazpokroy "Biominerilization of Calcium carbonate in structural aspects" Royal society of chemistry, volume. (9),2007 ;Page: 1156-1161.

[10]. VolodymyrIvanov, Jianchu“Appliations of Microorganisms to geotechnical for Bioclogging and Biocementation of soil insitu" Reviews in Environmental Science and Biotechnology, volume .7(2),2008;Page: 139-153. 